\section{The Ministry of Health}

THE seventeenth annual report of the Ministry of Health, recently issued, summarizes the work of the Ministry during 1935-36 (London : H.M. Stationery Office, 1936. 5s. net). The services administered by the Department involved expenditure amounting to $£ 159,500,000$. About one expectant mother in every two now makes use of local authorities' facilities for ante-natal examination, a steady increase on previous years. Maternal mortality was $3 \cdot 93$ per 1,000 births, the lowest figure since 1924. Infantile mortality, that is, deaths of infants less than one year of age, was 57 per 1,000 births, the lowest figure on record. The total deaths from all forms of tuberculosis fell below 30,000 for the first time on record. of other infectious diseases, diphtheria showed some decline in 1935, only one case of smallpox was notified in that year, the deaths from pneumonia were nearly 1,000 fewer, and scarlet fever and measles were less prevalent. Much progress is reported in slum clearance, abatement of overcrowding, and in town and country planning. As regards public assistance, progress continues to be made in eliminating small and old-fashioned country institutions, and vagrancy appears to be steadily declining. Some 11 million men and $5 \frac{1}{2}$ million women in England and Wales are now entitled to health insurance benefits, upon which $£ 27,780,000$ was spent in 1935 . The annual State contribution for widows, orphans, and old age pensions grows automatically by one million a year until 1943, and is now (1936-37) $£ 15,000,000$. The section upon food gives information on new administrative measures, and details of the examination of 143,831 samples of food and drugs, of which 7,972 were given adverse reports.

\section{The Nation's Health in 1935}

THE seventeenth annual report of the Chief Medical Officer of the Ministry of Health, which was published on December 4, covers the year 1935. The deaths numbered 477,401, an increase of 591 over 1934, the principal certified causes of death at all ages being, in order, (1) diseases of the heart and circulatory system, (2) cancer, (3) bronchitis, pneumonia and other respiratory diseases. Attention is directed to the changing age-distribution of the population. Since the beginning of the century, the proportion of persons under twenty-five years has fallen by nearly twenty-five per cent, due to the fall in the birth-rate, and the fall in the general death-rate, which increases the proportion in the older groups. This increasing longevity of the population, together with more accurate diagnosis, probably accounts for the increase of the number of deaths from cancer, which is a disease of the later ages, from 63,263 in 1934 to 64,507 in 1935 , and it is probably fallacious to assume that there is a real increase of cancer. For 1935, the incidence of scarlet fever, diphtheria, tuberculosis, venereal and rheumatic diseases has declined, and only one case of smallpox was notified. Attention is directed to the relation of food to health and disease, and to the extension of the maternity and child welfare services.

\section{Was Sherlock Holmes a Drug Addict?}

AN occasional correspondent contributes an amusing article to The Lancet of December 26 entitled "Was Sherlock Holmes a Drug Addict ?", as his friend Dr. Watson represented him as being. The correspondent's reply is in the negative on the following grounds. In the first place, Holmes was a man of immense mental resource and initiative, being an expert chemist, an accomplished linguist, an assiduous student of Black Letter texts, a capable performer on the violin, a composer and an authority on medieval music. Nor was he of the stuff of which cocaine addicts are made, who are sociable, lacking in mental capacity and need the stimulus of a drug to rouse their interest in life. The continued use of cocaine leads to physical, mental and moral degeneration. Holmes, on the other hand, was the most unsociable of men and showed no deterioration. in his mental powers, physical activity or character. The correspondent suggests that Holmes was playing a trick on Watson when he pretended to give himself an injection of cocaine and showed an arm dotted and scarred with numerous puncture marks.

\section{Institute for the Study of Animal Behaviour}

AN Institute for the Study of Animal Behaviour has been formed by a number of zoologists, naturalists, physiologists and psychologists with the object of promoting and encouraging research into animal behaviour. The Institute intends to act as a clearinghouse for information regarding work that is being done upon animal behaviour in all its aspects, and to bring together field and laboratory workers for the discussion of their problems. A quarterly bulletin is being issued, and meetings for the transaction of seientific business are held. Those whose work is concerned with animal behaviour in any of its aspects will materially assist the work of the Institute if they will send offprints of their papers to the honorary secretary. Dr. J. S. Huxley is president of the Institute, and Mr. F. B. Kirkman is honorary treasurer. All information regarding membership and activities may be obtained on application to the honorary secretary, R. C. Oldfield, Psychological Laboratory, Downing Place, Cambridge.

\section{The Making of Chemical Plant}

There is a school of economies which lays stress on the importance of exports in order that Great Britain may pay for its imports. At the same time, the home manufacturers ask for some measure of protection so that they can supply the home markets and maintain a manufacturing plant of sufficient size to ensure reasonable costs. An industry which has progressed quite rapidly in Great Britain since the Great War is that of making chemical plant, about which the Industrial Chemist of November has published some interesting statistics. The export trade has gone up from a figure of 100 in 1933 to 131 in the first nine months of 1936. The plant exported goes to less highly industrialized countries and, therefore, is not of the same complexity and costliness of design which the home market demands : 
thus the average value this year is $£ 67$ per ton. Australia and South Africa are now the chief customers for British chemical plant. Great Britain also imports chemical plant, and since there is increasing activity in the chemical industry, the amount of this has increased more than three-fold since 1935, though there are now signs of abatement. The average value per ton this year is $£ 143$. Most of the plant, which is generally of a highly specialized nature, has come from Germany. These figures give no indication of the activities of the British plant manufacturers in the home trade, but the same number of the Industrial Chemist seeks to remedy this by several pages of pictures of actual plant and new equipment which has been delivered this year, featured under the heading of "Progress".

\section{Forest Products Research}

THE report of the Forest Products Research Board for the year 1935 has been issued by the Department of Scientific and Industrial Research (London : H.M. Stationery Office, 1936). The report includes the report of the director of the Researeh Laboratory at Princes Risborough for the same year. The Board itself met only once during the year, when various pieces of research work under investigation were considered, as also the possibility of establishing a substation of the Laboratory in Seotland. The Board noted with appreciation that there was direct evidence of interest by industries concerned in the manufacture of both wooden and fibre-board boxes, as well as by users of such boxes, of the facilities now available in the new box-testing laboratory. The investigations into the physical properties of timber which have a direct influence on its behaviour during seasoning and when in use have been advanced; and the results, it is considered, promise ultimately to be of material importance to architects and others engaged in industries dependent upon timber. As a result of visits to the Laboratory by many representatives of firms engaged in the manufacture of timber and timber goods, and instructors in building science or woodworking at various technical schools, some of whom have spent periods of varying lengths at the Laboratory, a new departure has been instituted. To minimize the interference with the routine work which such visits involved, a short educational course of one week's duration was given in September of which full advantage was taken.

\section{An Alchemical Manuscript}

IN a reprint from Osiris $(2,220 ; 1936)$, W. J. Wilson, of the Library of Congress, Washington, deals with a treatise copied by Arnaldus de Bruxella at Naples between 1473 and 1490 , and purchased by Lehigh University, Pennsylvania, in 1881 for the price of ten dollars. It is a compendium of chemical and alchemical recipes of a type fairly well known through other manuseipts of similar date in Paris and elsewhere. Mr. Wilson gives an account of the contents of the manuscript with extracts, which are translated, and an index of names and technical terms. He shows how its contents are related to other treatises, and deals in separate sections with the origin and development of alchemical tradition, the operations of alchemy, allegorical and mystical aspects of alchemy and its relations to magic and medicine. This commentary, which is the fruit of a careful study of texts and literature on the history of alchemy, is provided with an excellent bibliography and is of very considerable value in presenting an accurate and concise statement of the position of modern research into the origins of alchemy and early chemistry. The scholarly treatment is on a much higher level than many accounts in that it takes into consideration the Chinese and Indian sources, without which no modern study can be said to have any particular significance.

\section{Decline in Malaria in Soviet Russia}

As the result of the energetic measures adopted by the Soviet authorities, the incidence of malaria in the U.S.S.R. has greatly declined. According to Prof. Sergiyev, head of the Malaria Department of the Commissariat of Health and director of the Central Tropical Institute, during the first six months of 1936 there was a drop of about 35 per cent in the number of malaria cases and of 40 per cent in the number of deaths from malaria as compared with the corresponding period of 1935 . With the object of destroying the malaria-carrying mosquitoes, two and a half million infested areas were sprayed with oil, partly by aeroplanes. Mosquito netting was introduced into the badly infested areas. 100 motorcars and 260 microseopes were supplied to the malaria stations. During the summer, 500 doctors and senior students took part in the anti-malarial campaign, which was carried on by 1,800 permanent malaria organizations.

\section{Tropical Pathology and Microbiology}

OwING to the increasing number of papers in the field of special pathology and microbiology hitherto published in the Chinese Medical Journal, which is primarily intended for clinical contributions, this material will now be published in a Supplement to the Chinese Medical Journal, of which the first number was issued last February. It forms a volume of the same size and format as the Journal, and contains 500 pages of text with 70 plates, and is published by the Chinese Medical Journal, Peiping, China, price $10 s$. The contents are divided into the three subjects : (1) pathology, (2) bacteriology and (3) parasitology. In addition, there is a valuable paper by R. J. C. Hoeppi on "Methods of Illustrating Scientific Papers", in which the apparatus for, and technique of, drawing, and the main processes now used for reproduction of illustrations, are described.

\section{Museum Exhibits de luxe}

At last the limit of the nature-group method of exhibiting museum specimens seems to have been reached, for Science Service announces that Prof. 